\title{
Correction to: Eliciting the public preferences for pharmaceutical subsidy in Iran: a discrete choice experiment study
}

\author{
Mansoor Delpasand ${ }^{1}$, Alireza Olyaaeemanesh ${ }^{2 *}$, Ebrahim Jaafaripooyan ${ }^{1}$, Akbar Abdollahiasl $^{3}$, \\ Majid Davari ${ }^{3}$ and Ali Kazemi Karyani ${ }^{4}$
}

\section{Correction to: J Pharm Policy Pract (2021) 14:59 https://doi.org/10.1186/s40545-021-00345-4}

Following the publication of the original article [1], the authors notified us of a few mistakes:

- In the Results section of the Abstract, "disease severity $(\beta=-0.143 ; \mathrm{SE}=0.043)$ " should actually read "cost burden for the government $(\beta=-0.140$; $\mathrm{SE}=0.050)$.

- In the Results section of the body of the article, the phrase "Increasing survival after treatment was the most important attribute in the present study (36\%), followed by promoting QoL (27\%), alternative treatment" should read "Increasing survival after treatment was the most important attribute in the present study (34\%), followed by promoting QoL (26.5\%), alternative treatment".

- In the 7th paragraph of the Discussions section, the phrase "The last attribute for entering a drug into the list of subsidized drugs was disease severity" should read "The fifth important attribute for entering a drug into the list of subsidized drugs was disease severity.".
- In the 8th paragraph of the Discussions section, the phrase "The fifth important attribute for entering a drug into the list of subsidized drugs was the cost burden for the government." should read "The last attribute for entering a drug into the list of subsidized drugs was the cost burden for the government."

- In Table 4, the values for the relative importance (last column) are changed:

- 36 becomes 34.1

- 27 becomes 26.6

- 17.20 becomes 22.6

- 13.10 becomes 7.8

- 3.40 becomes 4.1

- 3.30 becomes 4.8

The original article has now been corrected.

\section{Author details}

'Department of Health Management and Economics, School of Public Health, Tehran University of Medical Sciences, Tehran, Iran. ${ }^{2}$ Health Equity Research Center \& National Institute for Health Research, Tehran University of Medical Sciences, Tehran, Iran. ${ }^{3}$ Pharmacoeconomics and Pharmaceutical Administration, Tehran University of Medical Sciences, Tehran, Iran. ${ }^{4}$ Research Center for Environmental Determinants of Health, Kermanshah University of Medical Sciences, Kermanshah, Iran.

Published online: 09 September 2021 original author(s) and the source, provide a link to the Creative Commons licence, and indicate if changes were made. The images or other third party material in this article are included in the article's Creative Commons licence, unless indicated otherwise in a credit line to the material. If material is not included in the article's Creative Commons licence and your intended use is not permitted by statutory regulation or exceeds the permitted use, you will need to obtain permission directly from the copyright holder. To view a copy of this licence, visit http://creativecommons.org/licenses/by/4.0/. The Creative Commons Public Domain Dedication waiver (http://creativecommons.org/publicdomain/zero/1.0/) applies to the data made available in this article, unless otherwise stated in a credit line to the data. 


\section{Reference}

1. Delpasand M, Olyaaeemanesh A, Jaafaripooyan E, Abdollahiasl A, Davari $M$, Karyani AK. Eliciting the public preferences for pharmaceutical subsidy in Iran: a discrete choice experiment study. J Pharm Policy Pract. 2021;14:59. https://doi.org/10.1186/s40545-021-00345-4.

\section{Publisher's Note}

Springer Nature remains neutral with regard to jurisdictional claims in published maps and institutional affiliations. 